\title{
MORFOLOGIA COMPARADA DO TÓRAX DAS ESPÉCIES SULBRASILEIRAS DE MORPHINAE (LEPIDOPTERA, NYMPHALIDAE) ${ }^{1}$
}

\author{
Ivana Gavassi Bilotta ${ }^{2}$
}

\begin{abstract}
COMPaREI THORAX MORPHOLOGY OF SOUTH BRAZILIAN MORPHINAE SPECIES (LEPIDOPTERA, NYMPHALIDAE). A detailed study of the thorax morphology and his appendices of adults, males and fenales, of the following south Brazilian Morphinae species (Lepidoptera, Nymphalidae) is presented: Morpho helenor violaceus Fruhstorfer, 1912, Iphimedeia hercules (Dalman, 1823), Iphixibia anaxibia (Esper, 1801). Cytheritis portis thamyris (C. Felder \& R. Felder, 1867), Cytheritis aega (Hucbner, 1822), Pessonia calenaria (Perry, 1811). Grasseia menelaus nestira (Hucbner, 1821).

KEY WORDS. Nymphalidac, Morphinae, morphology, thorax
\end{abstract}

Esta é a segunda parte dos estudos morfológicos de adultos das espécies sulbrasileiras de Morphinae (BILOTTA 1993), onde se apresenta aspectos externos comparados do tórax. As seguintes espécies foram estudadas: Morpho helenor violaceus Fruhstorfer, 1912, Iphimedeia hercules (Dalman, 1823), Iphixibia anaxibia (Esper, 1801), Cytheritis portis thamyris (C. Felder \& R. Felder, 1867), Cytheritis aega Huebner, 1822), Pessonia catenaria (Perry, 1811), Grasseia menelaus nestira (Huebner, 1821).

\section{MATERIAL E MÉTODOS}

Os trabalhos de DOUbLEDAy (1846-1852), CRAMPTON (1917), SNODGRASS (1935), Madden (1944), Costa Lima (1950), Ehrlich (1958a,b), Niculescu (1968, 1976, 1978), MATSUda (1970), EATON (1971), COMMON (1973), CASAgrande (1979), Sbordoni \& Forestiero (1985) foram de grande importância para o estudo morfológico comparativo interespecífico. Para o embasamento sistemático, os trabalhos utilizados foram STAUDINGER (1884-1888), FruHSTORFER (1912-1913), LE MOULT \& RÉAL (1962-1963), D'Abrera $(1984,1987)$, Devries (1985).

O estudo da morfologia externa do tórax seguiu a mesma metodologia utilizada na cabeça (BıLOTTA 1993).

Para a observação da venação alar, as"asas foram destacadlas e descoloridas, pelo seguinte processo: imersão em álcool $70 \%$ para retirada da gordura, em seguida mergulhadas em hipoclorito de sódio onde permanecem até desaparecer

1) Contribuição número 795 do Departamento de Zoologia, Universidade Federal do Paraná.

2) Departamento de Zoologia, Universidade Federal do Paraná, Caixa Postal 19020, 81531-970 Curitiba, Paraná, Brasil. Bolsista do CNPq. 
toda a coloração das escamas, retornando ao álcool $70 \%$ para neutralizar o efeito do hipoclorito de sódio. Para secar, foram colocadas entre folhas de papel filtro e lâminas de vidro a fim de evitar enrugamentos. Para as pernas, seguiu-se o processo utilizado na cabeça.

Desenhos da venação alar foram feitos com auxílio de um ampliador fotográfico.

\section{TÓRAX}

Unindo o tórax à cabeça, está a região cervical ou cérvix, exceto pela presença do pequeno par de escleritos cervicais, a região é totalmente membranosa. Esclerito cervical com formato de um " $\mathrm{T}$ " deitado, articulando-se anteriormente com a ponte pós-ocipital e posteriormente com as margens anteriores das propleuras (Fig. 1A-G). Ocorre uma variação muito grande no formato dessa estrutura: $M$. helenor violaceus haste direcionada anteriormente, curvada e com ápice afilado, haste posterior aproximadamente duas vezes maior que a anterior, reta e os ápices atilados (Fig. 1A); I. hercules haste anterior reta e ápice afilado, haste posterior pouco maior que a anterior, levemente constrita na região mediana, sendo a porção superior curvada e os ápices arredondados (Fig. 1B); I. anaxibia haste anterior levemente curvada e ápice arredondado, haste posterior maior que a anterior, levemente constrita na região mediana, com a porção superior curvada e ápice arredondado, porção inferior reta e ápice afilado (Fig. 1C); C. portis thamyris haste anterior maior, reta e ápice afilado, haste posterior aproximadamente uma vez e meia menor que a anterior, levemente constrita na região mediana e curvada, ápice da porção superior afilado e o da porção inferior arredondado (Fig. 1D); C. aega haste anterior levemente curvada e o ápice afilado, haste posterior aproximadamente do mesmo tamanho que a anterior, reta e ápices afilados (Fig. 1E); P. catenaria haste anterior levemente curvada e ápice arredondado, haste posterior maior que a anterior, sendo a porção superior bem reduzida e ápice afilado e o da porção inferior arredondado (Fig. IF); G. menelaus nestira haste anterior maior, levemente curvada e ápice arredondado, haste posterior reta, sendo a porção superior reduzida e ápice afilado e o da porção inferior arredondado (Fig. 1G).

O tórax apresenta três segmentos: pró, meso e metatórax, de acordo com sua posição em relação à cabeça. Cada segmento está dividido em uma região dorsal, tergo ou noto, uma ventral, esterno, e duas laterais, pleuras. Cada segmento apresenta um par de pernas e os dois últimos um par de asas.

\section{Protórax}

O menor dos três segmentos torácicos, contém o primeiro par de pernas. Constitui-se de pronoto, propleura e prosterno.

$\mathrm{O}$ pronoto, com formato de um cálice, apresenta três pontas anteriores e uma posterior. A posterior articula-se com a margem anterior do mesotórax. As duas pontas laterais anteriores terminam abaixo dos patágios e a mediana entre os patágios. Patágios ovalados em todas as espécies, com exceção de $C$. portis 


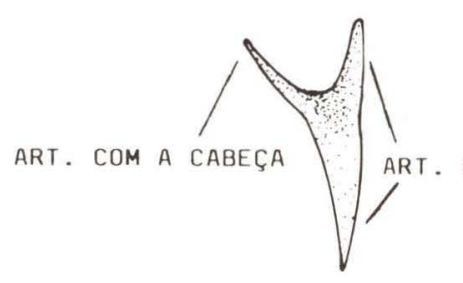

A

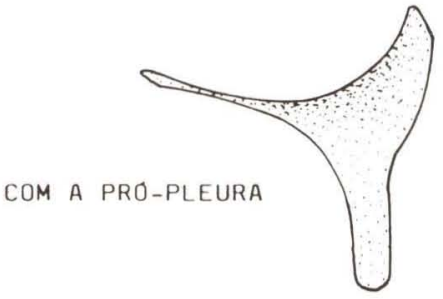

B

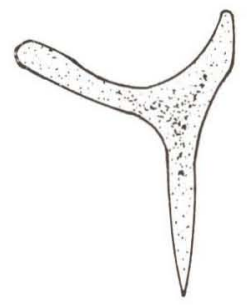

C
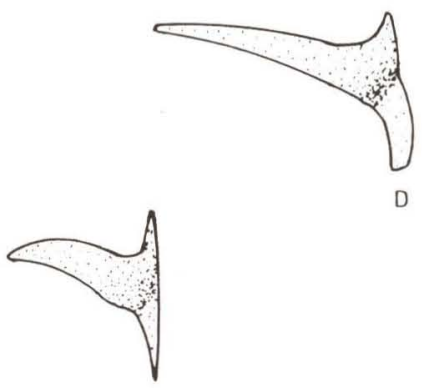

D

$\mathrm{E}$

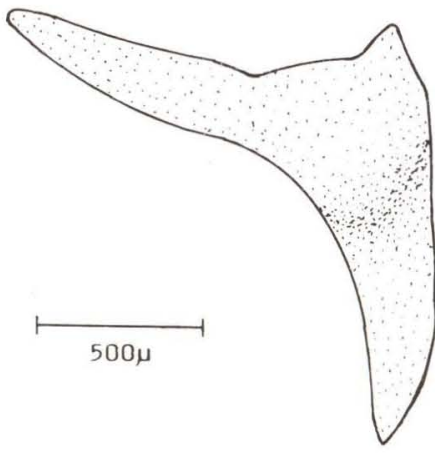

F

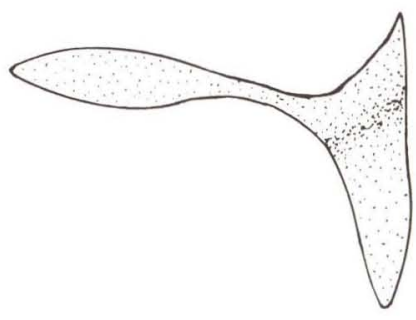

1

Fig. 1. Esclerito cervical, vista lateral. (A) M. helenor violaceus; (B) I. hercules; (C) I. anaxibia; (D) C. pontis thamyris; (E) C. aega; (F) P. catenaria; (G) G. menelaus nestira.

thamyris quadrangulares (Fig.5); apresentam-se pouco esclerotisados e situam-se na porção ântero-dorsal do protórax (Figs 2 a 8 ).

As propleuras, laterais ao pronoto, articulam-se com o esclerito cervical no terço anterior e superior, prolongam-se ventralmente, onde se unem por uma sutura mediana-longitudinal, o discrime (Figs 16 a 22). Em $M$. helenor violaceus e I. anaxibia, os alvéolos coxais não circundados na porção posterior pela propleura (Figs 16 e 18); nas demais espécies, a propleura circunda ventralmente toda extensão dos alvéolos coxais (Figs 17, 19 a 22). Látero-internamente, as propleuras 

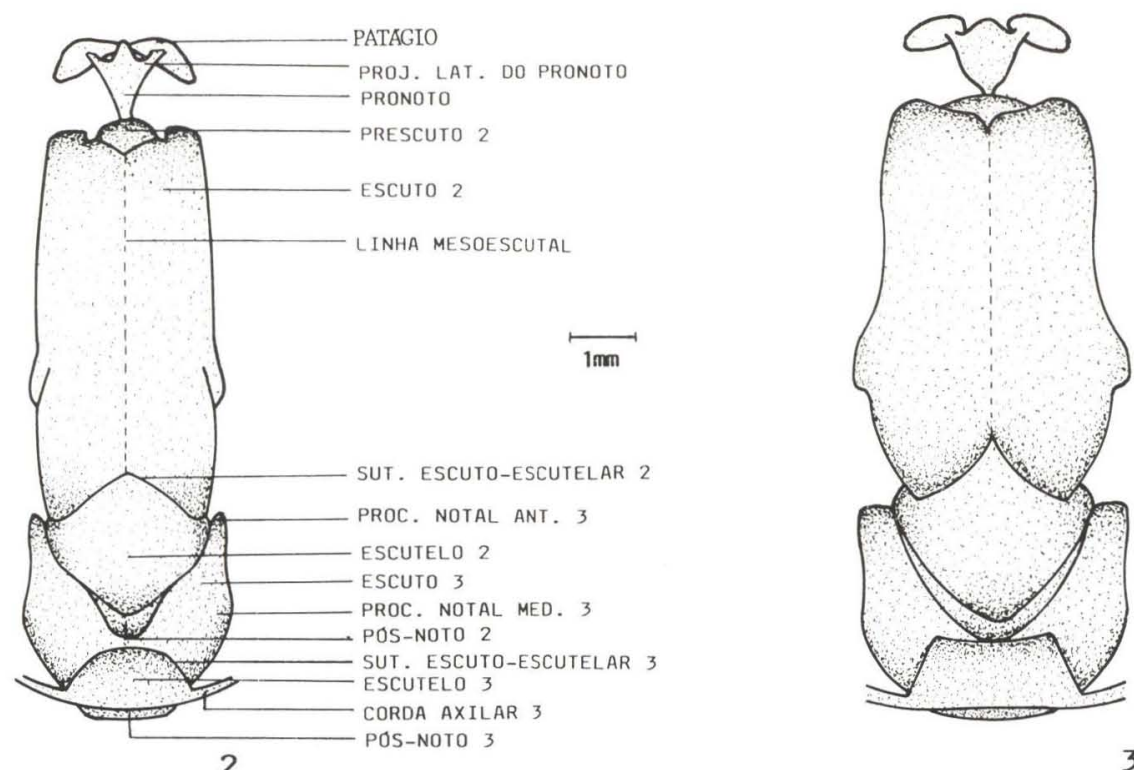

2

Figs 2-3. Tórax, vista dorsal. (2) M. helenor violaceus; (3) I. hercules.

apresentam pequena projeção para o interior dos alvéolos coxais formando a articulação pleural da coxa. Seguindo o discrime, na linha mediana-ventral, existe um pequeno esclerito alongado, furcasterno (Figs 16 a 22). Posterior a este, o espinasterno, de formato triangular, articula-se com a margem anterior do esternopleurito em todas as espécies, com exceção de $I$. hercules circundado por membrana (Fig. 17). Na membrana intersegmental do pró e mesotórax, lateralmente, situa-se o primeiro espiráculo, ovalar, marginado por um estreito esclerito espiracular (Figs 9 a 15).

\section{Mesotórax}

O maior dos três segmentos torácicos, contém o primeiro par de asas e o segundo par de pernas. Constitui-se de mesonoto, mesopleura e mesoesterno.

O mesonoto, grande, fortemente esclerotisado, formado por quatro escleritos: prescuto, escuto, escutelo e pós-noto. Prescuto, o menor, articula-se anteriormente com o pronoto e posteriormente com o escuto. CASAGRANDE (1979) cita que o prescuto emite duas projeções, uma a cada lado, constituíndo os processos pré-alares estendendo-se látero-ventralmente ao braço tegular (Figs 2 a 8). Escuto, maior, dorsalmente convexo, apresenta uma linha mediana que se estende do prescuto até o escutelo, linha mesoescutal. Placas suralares separadas do escuto pelo sulco escutal, localizam-se na margem látero-anterior do escuto, separado do escutelo pela sutura escuto-escutelar e com a forma de um V invertido (Figs 2 a 15). Escutelo, tem formato triangular, é o segundo em tamanho (Figs 2 a 15). Pós-noto está separado do escutelo por uma estreita faixa membranosa. A 


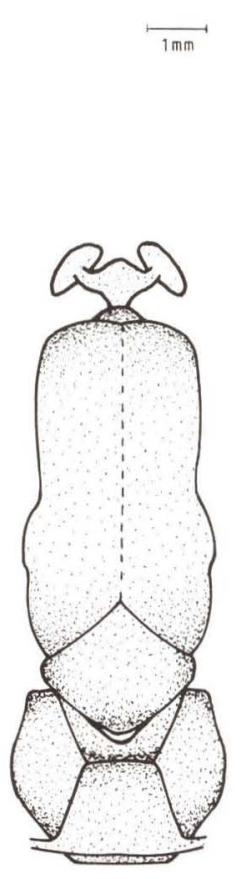

4

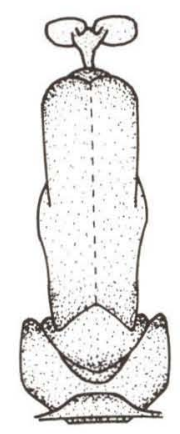

5

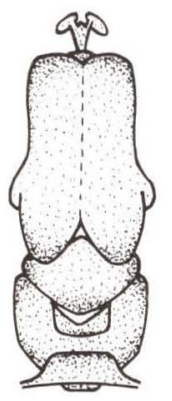

6

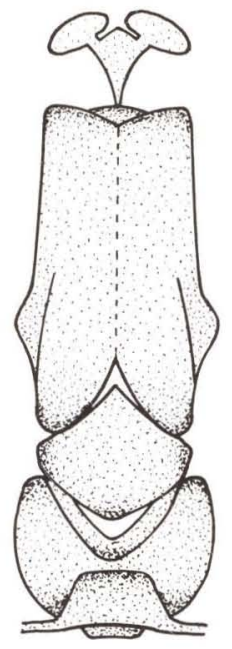

7

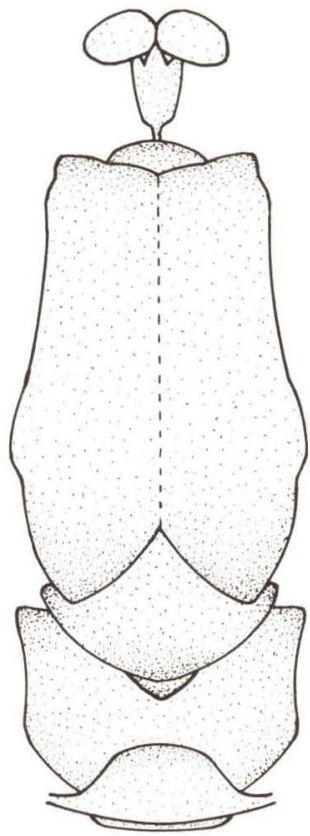

8

Figs 4-8. Tórax, vista dorsal. (4) I. ancuibia: (5) C: portis thamyris: (6) C: acga: (7) P. calenaria: (8) G. menelats nestira.

margem lateral do pós-noto está intimamente ligada com a porção pós-alar do epimero (Figs 9 a 15 ).

Mesopleura dividida longitudinalmente pela sutura pleural, em uma região anterior, o episterno, e uma posterior, o epimero. Sutura pleural estende-se da sutura marginopleural em direção ao mesonoto (Figs 9 a 15). Episterno dividido pela sutura anepisternal em dois escleritos: anepisterno, menor e superior; em $M$. helenor violaceus, I. hercules, $C$. aega e $G$. menelaus nestira, este localiza-se acima, mas entre o pré-episterno e o catepisterno (Figs 9, 10, 13, 15); em $I$. anaxibia, $C$. portis thamyris e $P$. catenaria localiza-se acima do pré-episterno (Figs $11,12,14)$. O outro esclerito, ventral e maior, o catepisterno, separado pela sutura pré-coxal, que parte látero-anteriormente da sutura pleural chegando ao discrime do esternopleurito, este esclerito prolonga-se para a parte ventral do tórax, entre as coxas e unindo-se através do discrime (Figs 9 a 22). Ventralmente o catepisterno se aloja entre o pré-episterno e o esternopleurito (Figs 16 a 22). Pré-episterno, triangular, situado anterior e separado do catepisterno pela sutura pré-episternal, termina ventralmente no espinasterno (Figs 9 a 22). Epimero posterior e separado do episterno pela sutura pleural, apresenta três partes: uma anterior, o pré-epimero; 


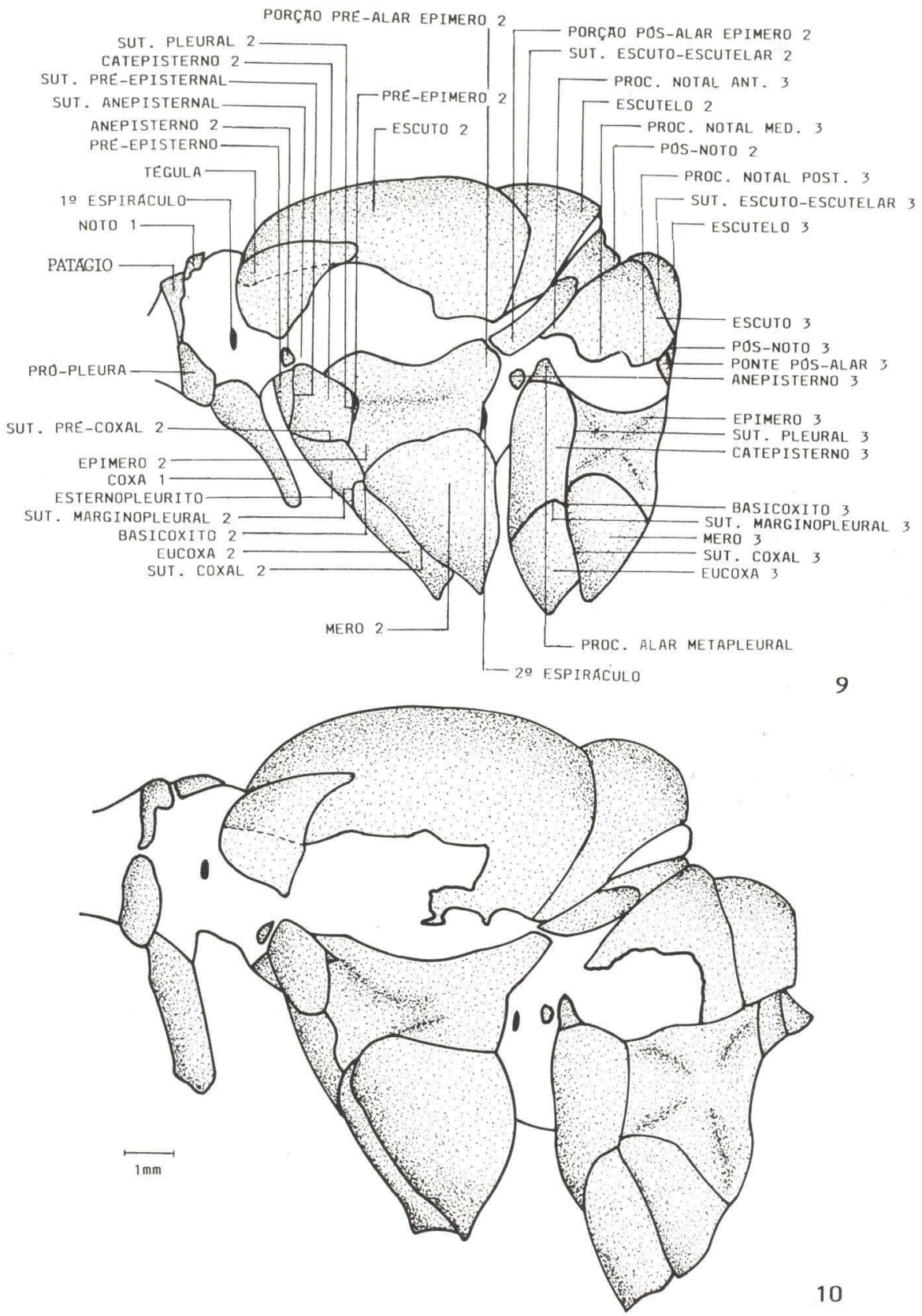

Figs 9-10. Tórax, vista lateral. (9) M. helenor violaceus: (10) I. hercules. 

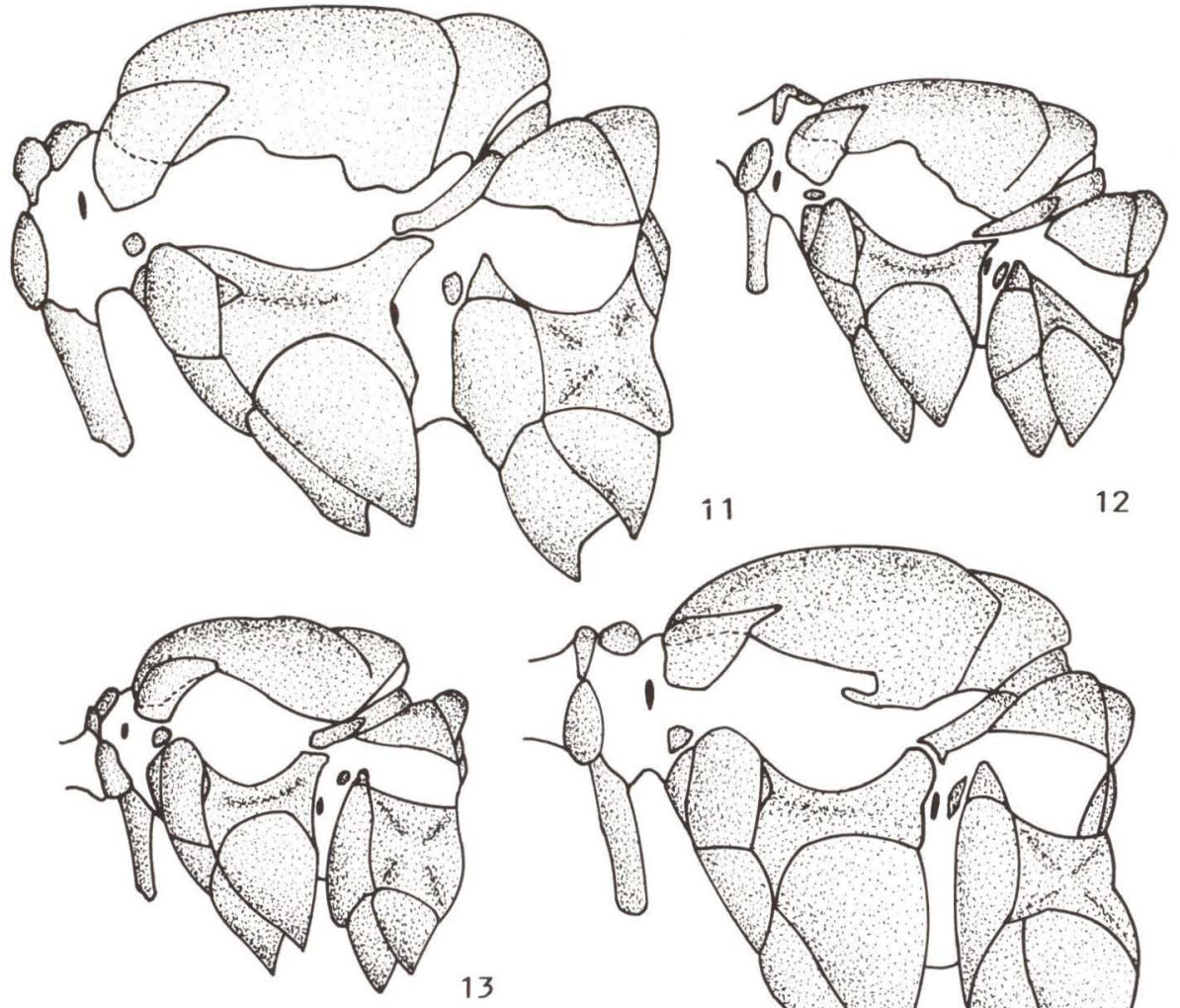

13

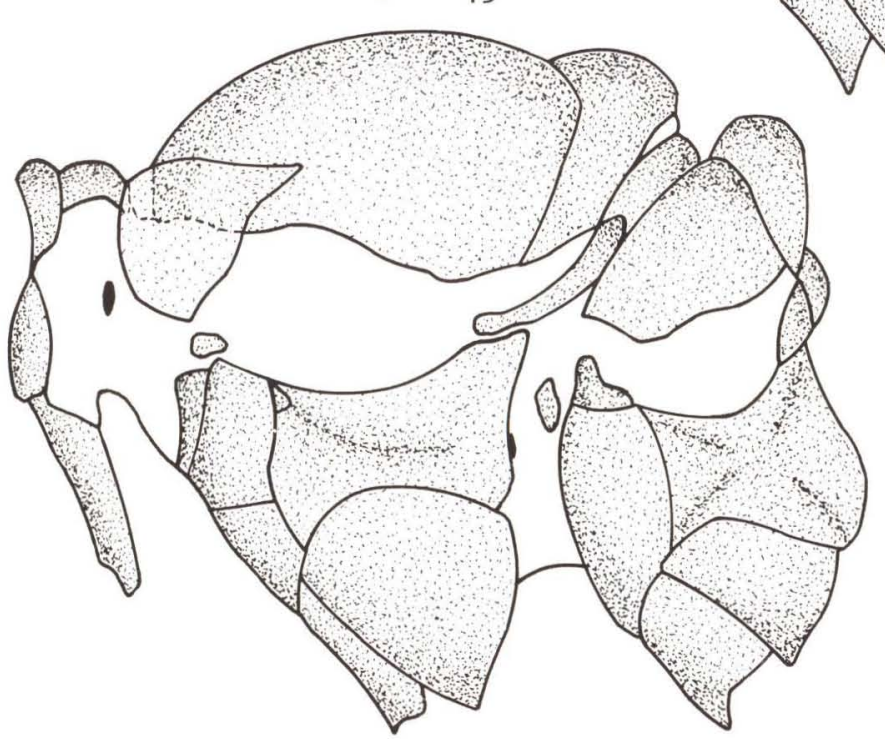

15

Figs 11-15. Tórax, vista lateral. (11) I. anaribia; (12) C. pertis thamyris; (13) C: aega; (14) $P$. catenaria: (15) G. menelaus nestira. 

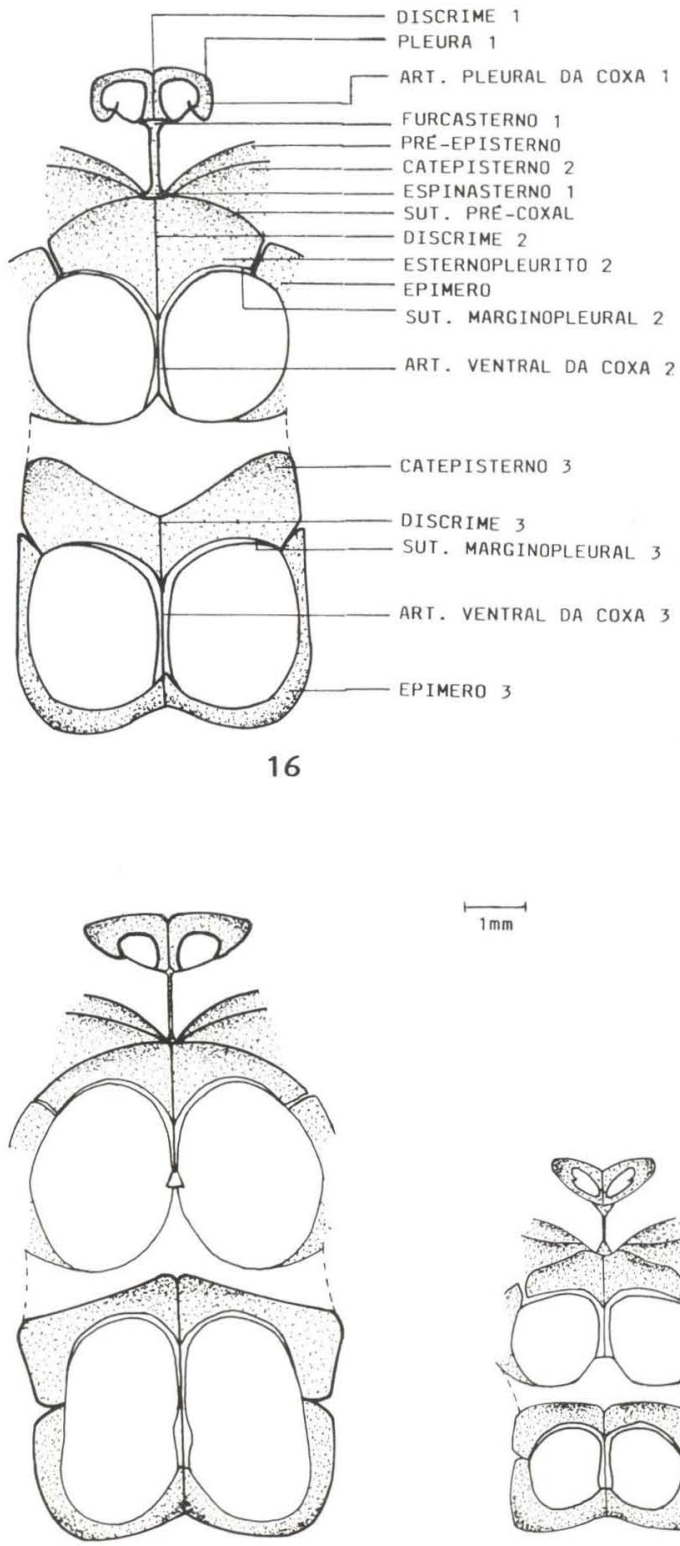

18
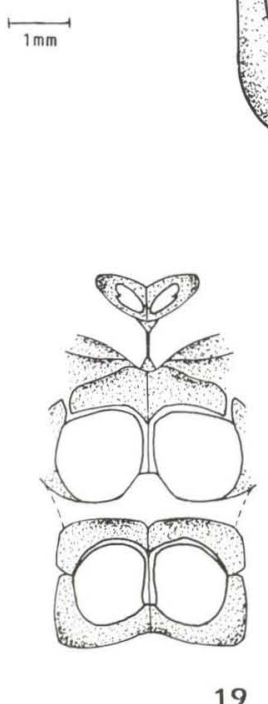

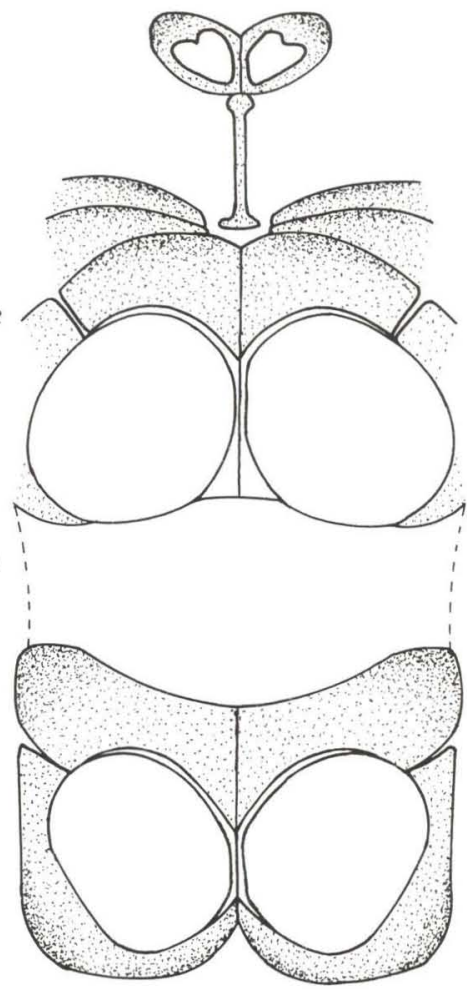

17

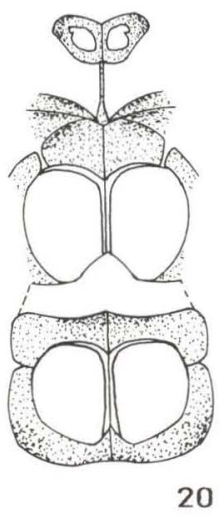

Figs 16-20. Tórax, vista ventral. (16) M. helenor violaceus: (17) I. hercules: (18) I. anaxibia: (19) C. portis thamyris; (20) C. aega.

Revta bras. Zool. 11 (4): $691-713,1994$ 

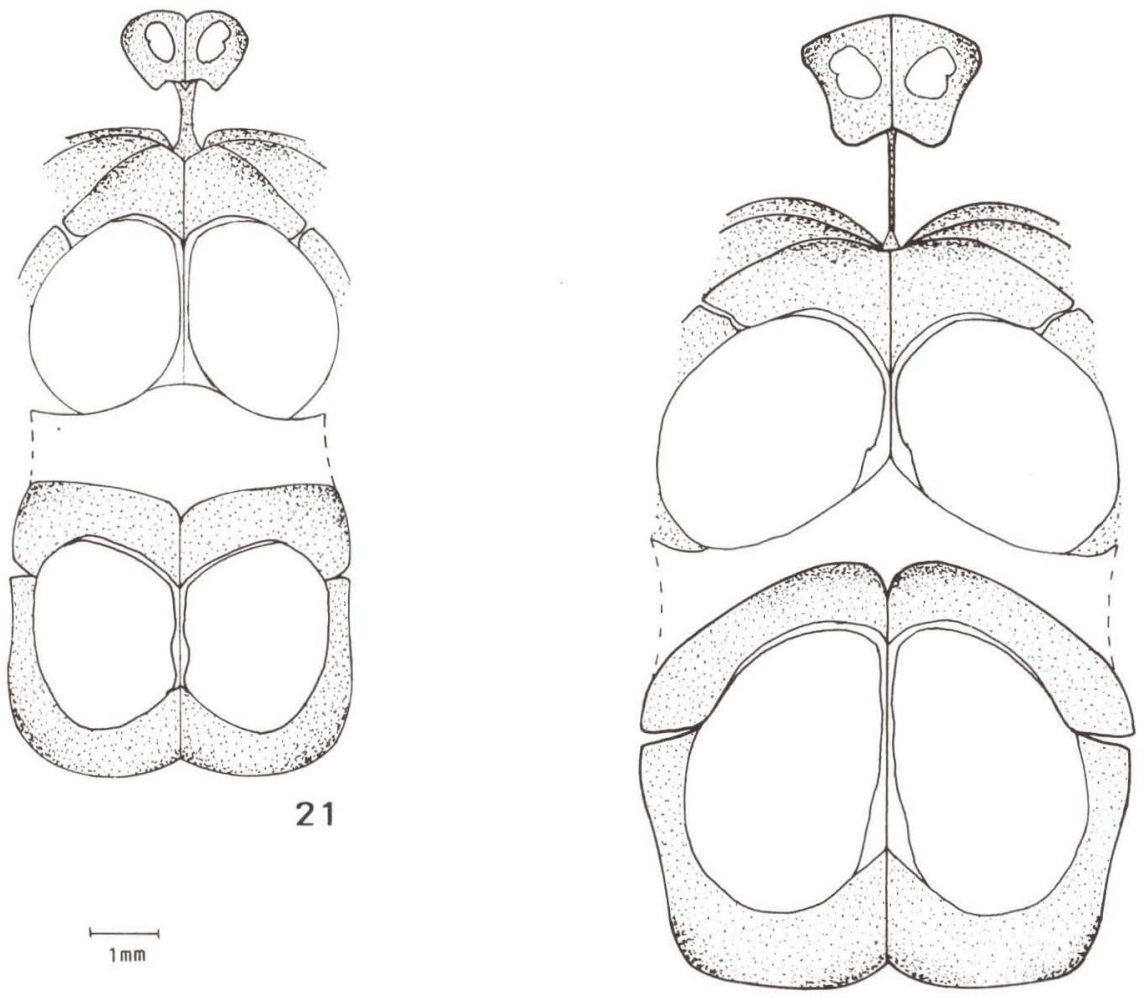

22

Figs 21-22. Tórax, vista ventral. (21) P. catenaria; (22) G. menelaus nestira.

uma mediana, a porção pré-alar do epimero; e a posterior, separada por membrana, a porção pós-alar do epimero, com o formato de um estreito retângulo projetandose até o pós-noto (Figs 9 a 15). Toda a margem dorsal do epimero voltada para o interior do corpo através de uma forte e nítida dobra do tegumento, enquanto a margem ventral contorna o mero. Entre o mesepimero e o metapisterno, na membrana, está o segundo espiráculo, pouco maior que o primeiro (Figs 9 a 15).

\section{Metatórax}

Último segmento do tórax, contém o segundo par de asas e o terceiro par de pernas. Constitui-se de metanoto, metapleura e metaesterno.

Metanoto formado por três escleritos: escuto, escutelo e pós-noto. Escuto formado por duas placas dorso-laterais e ligadas dorsalmente através de uma estreita faixa mediana em $M$. helenor violaceus, C. portis thamyris, C. aega, P. catenaria e G. menelaus nestira (Figs 2, 5 a 8); em I. hercules e I. anaxibia esta faixa ausente (Figs 3 e 4). Lateralmente, marcando o fim do escuto, está o sulco 


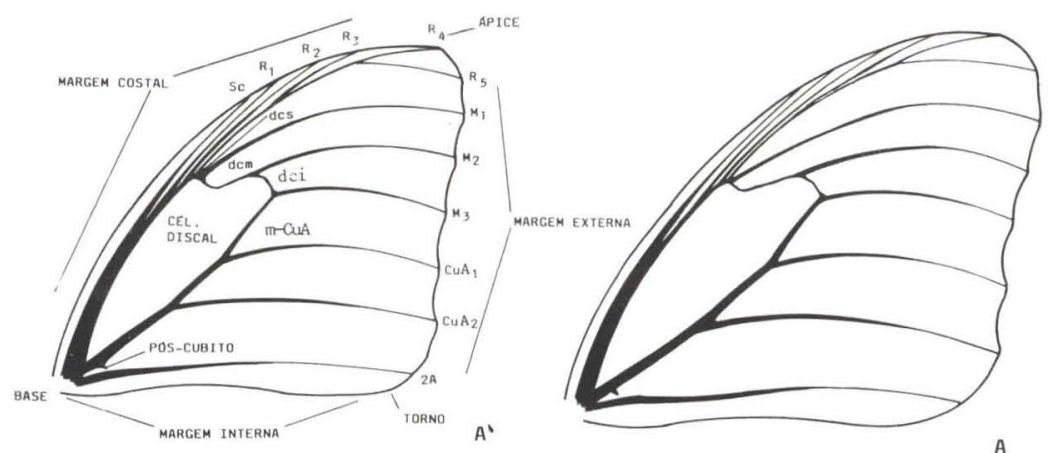

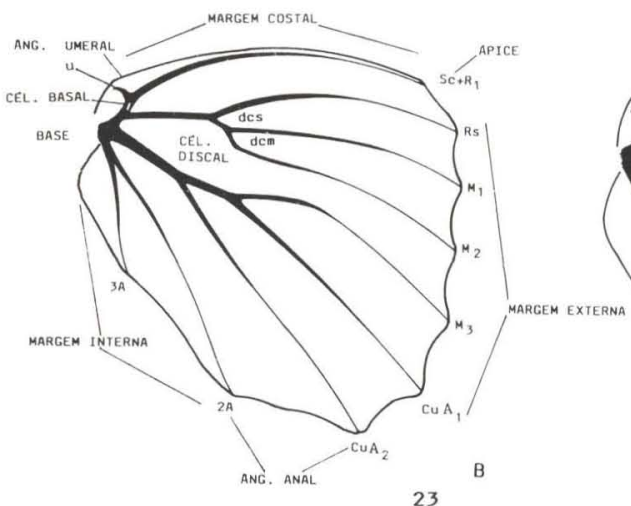

23

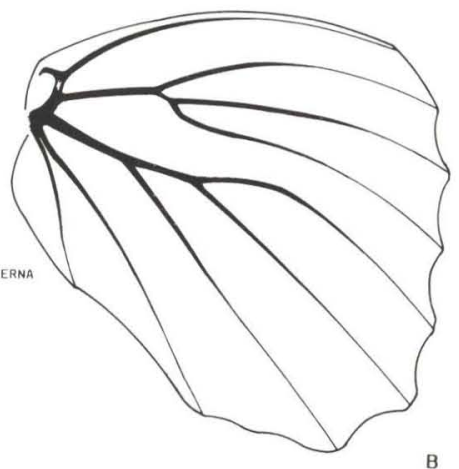

24

Figs 23-24. Venação, M. helenor violaceus. (23) Macho; (24) fềmea. (A) Asa anterior, (B) asa posterior.

escutal, sendo que na parte anterior está o processo notal anterior e na parte mediana, o processo notal mediano, estes articulam-se com o primeiro esclerito axilar, e na parte posterior, representando uma projeção mais distinta, o processo notal posterior, que se articula com o terceiro esclerito axilar (Figs 2 a 22). Escuto separado do escutelo pela sutura escuto-escutelar (Figs 2 a 15). Escutelo quadrangular, estende-se lateralmente até a pleura, formando a corda axilar (Figs 2 a 8). Pós-noto menor, prolonga-se látero-ventralmente até encontrar o epimero, formando assim a ponte pós-alar (Figs 2 a 15).

Metapleura, dividida pela sutura pleural em episterno e epimero. Esta sutura, longitudinal, estende-se da sutura marginopleural até o processo alar metapleural, acima do catepisterno (Figs 9 a 15). Episterno divide-se em anepisterno e catepisterno através da sutura anepisternal. Anepisterno, reduzido e ovalado, situa-se ântero-dorsalmente ao catepisterno. Catepisterno maior, separado da eucoxa pela sutura marginopleural, ambos descem ventralmente unindo-se na porção médio-ventral pelo discrime. Projeções ventral e mediana continuam em direção caudal, formando lateralmente e internamente a articulação ventral da coxa (Figs 9 a 22). Epimero maior e quadrangular (Figs 9 a 15), com exceção de 

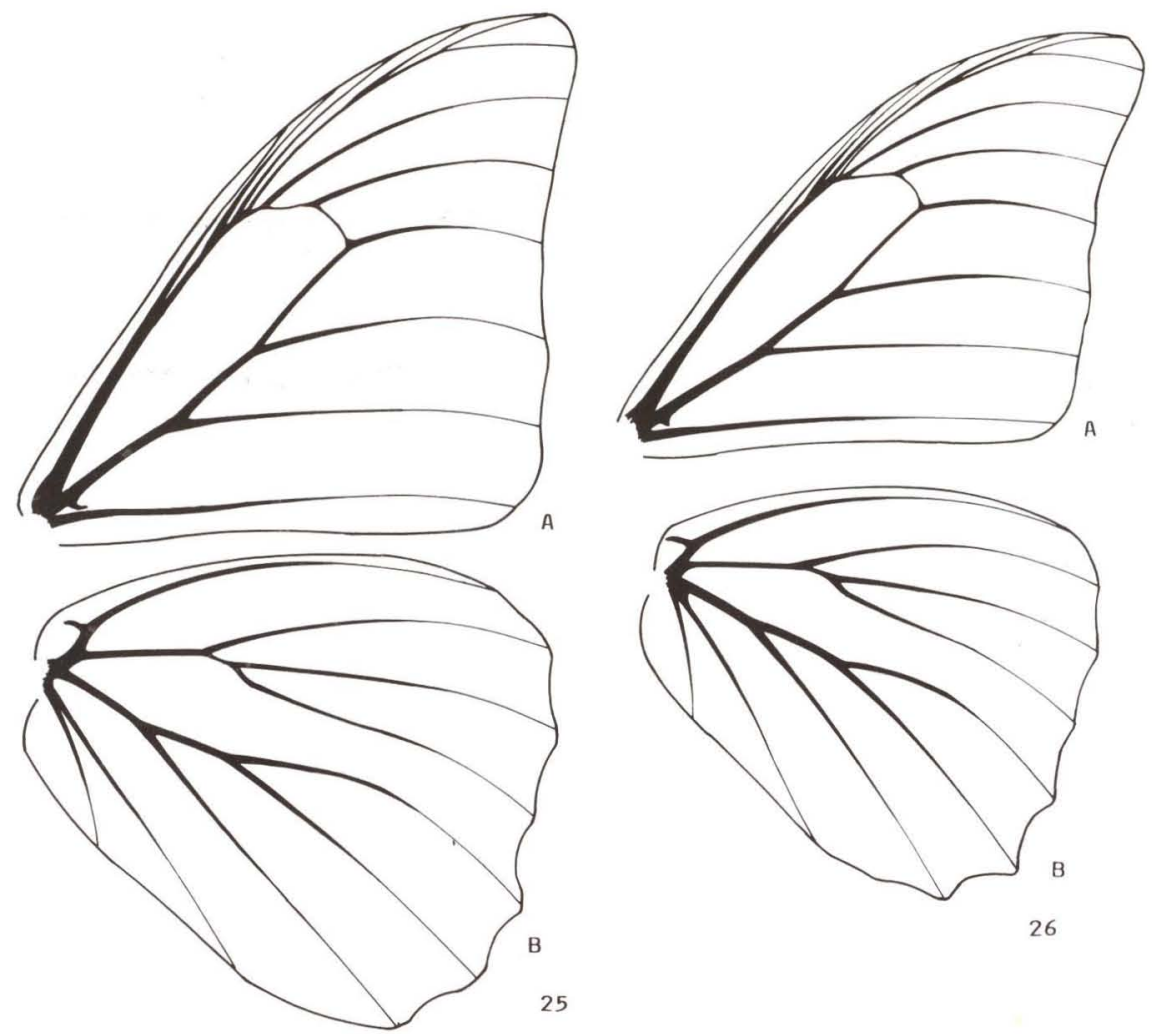

Figs 25-26. Venação, $I$. hercules. (25) Macho: (26) fềmea. (A) Asa anterior, (B) asa posterior.

C. portis thamyris onde se apresenta achatado dorso-ventralmente com o formato retangular (Fig. 12); em $M$. helenor violaceus, I. hercules e $P$. catenaria contorna as porções posterior e lateral externa do mero (Figs 16, 17, 21) ou apenas metade desta como em I. anaxibia, $C$. portis thamyris, $C$. aega e $G$. menelaus nestira (Figs 18 a 20 , 22). Metatórax sem sutura pré-coxal e esternopleurito.

\section{APÊNDICES DO TÓRAX}

\section{ASAS}

Distinguem-se três regiões nas asas: base, ápice e ângulo anal ou torno. Entre a base e o ápice, a margem costal ou costa; entre o ápice e o ângulo anal, a margem externa e entre o ângulo anal e a base, a margem interna ou anal (Figs 23 a 36). Na asa posterior, pouco acima do término da veia umeral, tem-se o ângulo umeral. 

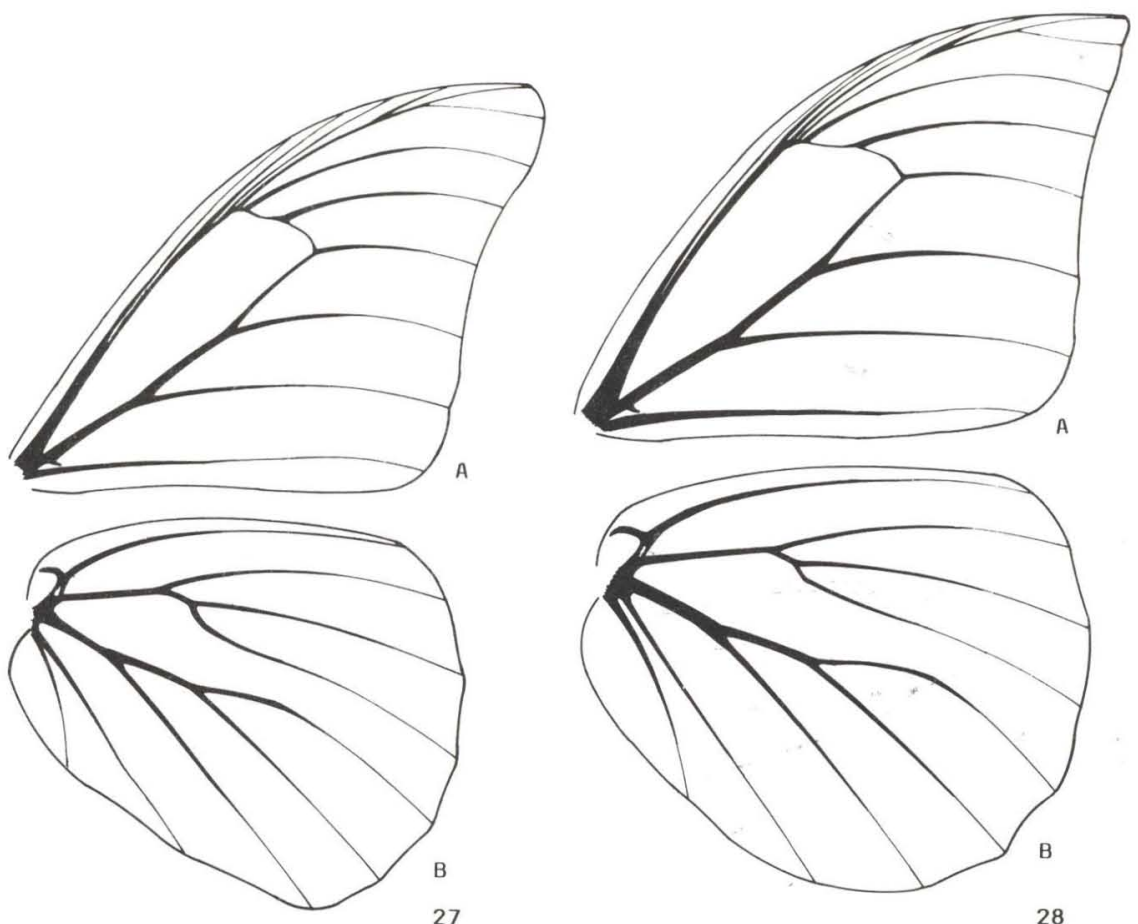

28

Figs 27-28. Venação, I. anaxibia. (27) Macho; (28) fêmea. (A) Asa anterior, (B) asa posterior.

Asa anterior triangular, margem externa reta ou suavemente ondulada e ápice não projetado em $C$. portis thamyris e $P$. catenaria (Figs 29, 30, 33, 34); em $I$. hercules, $I$. ancaxibia e $C$. aega margem externa reta ou suavemente ondulada e ápice projetado (Figs 25 a 28, 31,32); em $M$. helenor violaceus margem externa ondulada e ápice não projetado (Figs 23, 24); em $G$. menelaus nestira margem externa ondulada e ápice projetado (Figs 35,36). Venação da asa anterior mais complexa, constituída por:

1) Subcosta (Sc): mais espessa. Em I. hercules, $C$. portis thamyris, $P$. catenaria e $G$. menelaus nestira (fêmea), Sc termina antes do início de $\mathrm{M}_{2}$ (Figs $25,26,29,30,33,34,36)$; em $M$. helenor violaceus termina coincidindo com o início de $\mathrm{M}_{2}$ (Figs 23, 24); em I. anaxibia, C. aega e G. menelaus nestira (macho), termina após o início de M2 (Figs 27, 28, 31, 32, 35). Veias Sc e Rádio, em todas as espécies, unidas até após a metade proximal do maior comprimento da célula discal (Figs 23 a 36). Em I. anaxibia, exceção, unidas até antes da metade proximal do maior comprimento da célula discal (Figs 27, 28).

2) Rádio ( $R$ ): com 5 ramos (radiais): $R_{1}, R_{2}, R_{3}, R_{4}, R_{5}$. Inicialmente uma única veia, pouco antes da metade de sua total extensão, ramifica-se em $R_{1}$, que termina antes do ápice, na margem costal; a porção que continua, Rs, mais a frente 

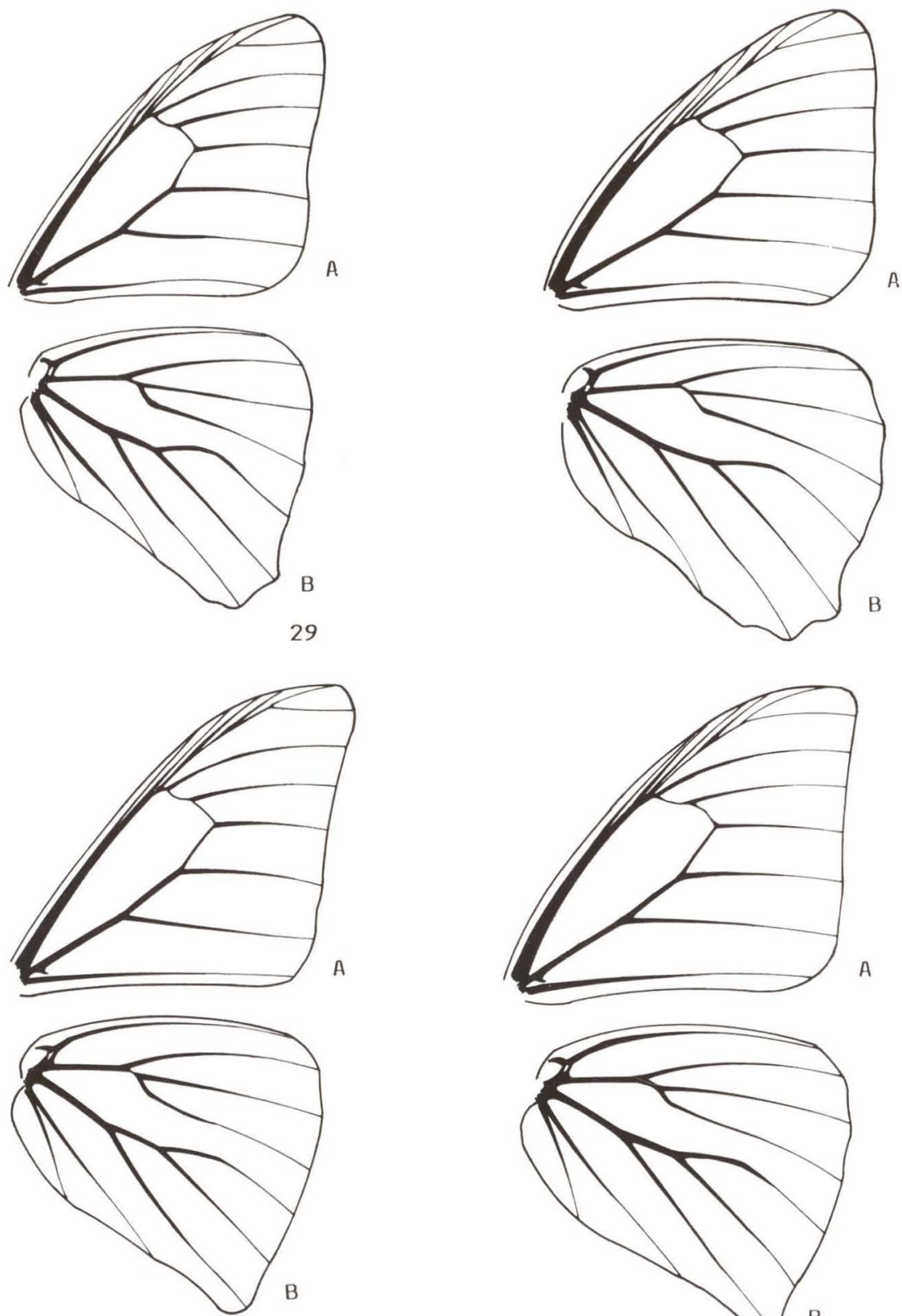

31

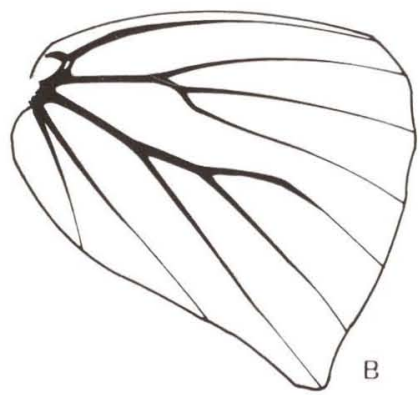

Figs 29-32. Venação. (29) C. portis thamyris, macho; (30) C. portis thamyris, fêmea; (31) C. acga. macho; (32) C. acga, fêmea. (A) Asa anterior, (B) asa posterior. 

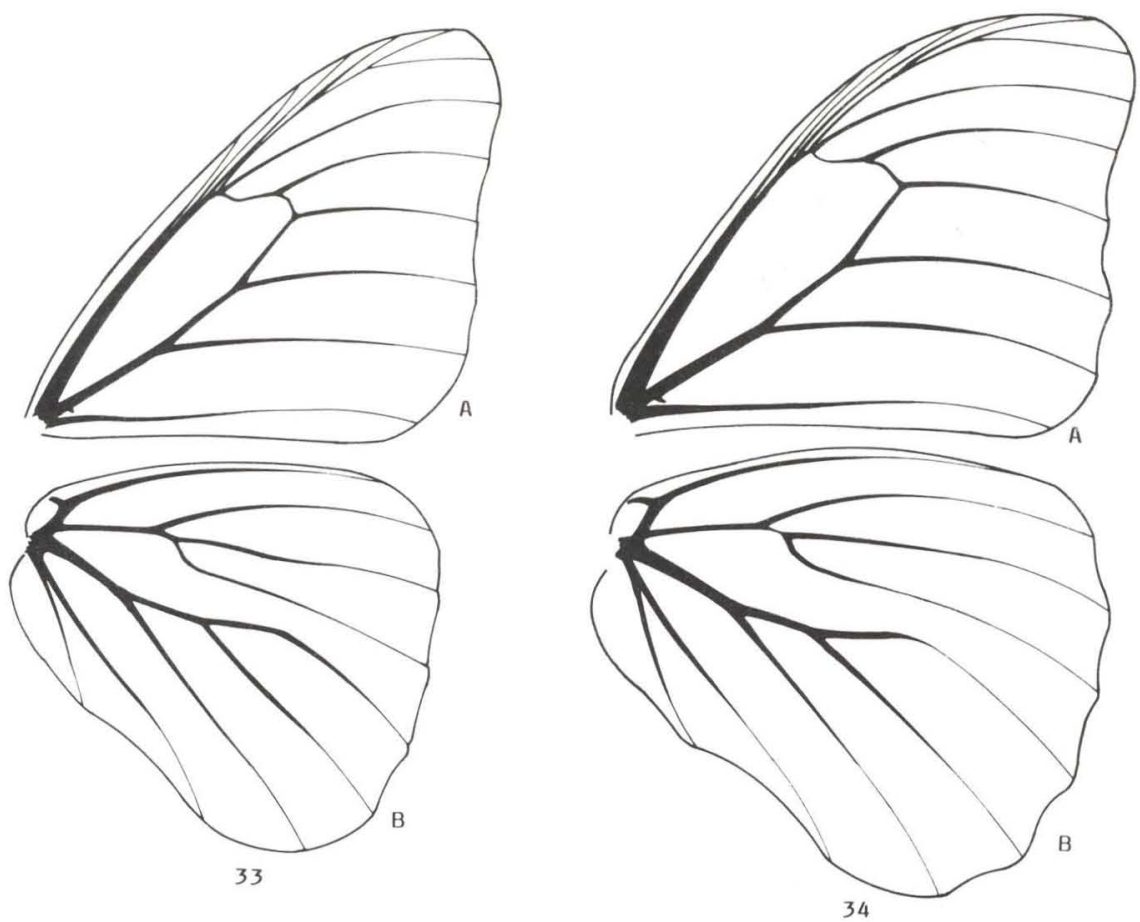

Figs 33-34. Venação P. catenaria. (33) Macho; (34) Rèmea. (A) Asa anterior, (B) asa posterior.

origina $\mathrm{R}_{2}$, esta corre paralela e termina pouco depois de $\mathrm{R}_{1}$, antes do ápice, na margem costal. Em direção ao ápice forma-se $\mathrm{R}_{3}$. Em $M$. helenor violaceus (macho), I. hercules, I. anaxibia, P. catenaria (macho) e G. menelaus nestira (macho), $\mathrm{R}_{3}$ se origina posteriormente ao ângulo distal inferior da célula discal (Figs 23, 25 a 28, 33, 35). Em M. helenor violaceus (fêmea) é anterior a este ângulo (Fig. 24); em $C$. portis thamyris, $C$. aega, $P$. catenaria (fềmea) e $G$. menelaus nestira (fềmea) coincide com o ângulo (Figs 29 a 32, 34, 36). O ramo que continua, se ramifica em $\mathrm{R}_{4} \mathrm{e} \mathrm{R}_{5}$. Em $M$. helenor violaceus, $I$. hercules, $I$. anaxibia (fêmea), $C$. aega (macho), $P$. catenaria e G. menelaus nestira, $\mathrm{R}_{3}$ mais longa que $\mathrm{R}_{4}$ (Figs 23 a 26, 28, 31, 33 a 36); em $I$. anaxibia (macho), $C$. portis thamyris e $C$. aega (fêmea) mais curta que $\mathrm{R}_{4}$ (Figs 27, 29, 30, 32). Todas as espécies tem $\mathrm{R}_{4}$ terminando no ápice, exceção de $C$. aega (tềmea) e $G$. menelaus nestira onde $\mathrm{R}_{4}$ termina na margem costal, próximo ao ápice (Figs 32, 35, 36). $I$. ancaxibia (fềmea), única que tem $\mathrm{R}_{4}$ maior que $\mathrm{R}_{5}$ (Fig. 28).

3) Média (M): próxima ao meio da asa, divide-se em três ramos (medianas): $\mathrm{M}_{1}, \mathrm{M}_{2}$ e $\mathrm{M}_{3}$, que correm paralelas até atingirem à margem externa da asa.

4) Cúbito-Anterior $(\mathrm{CuA})$ : inicialmente veia única, bifurca-se em dois ramos (cubitais anteriores): $\mathrm{CuA}_{1}$ e $\mathrm{CuA}_{2}$ (NIELSEN \& COMMON 1991) que correm 


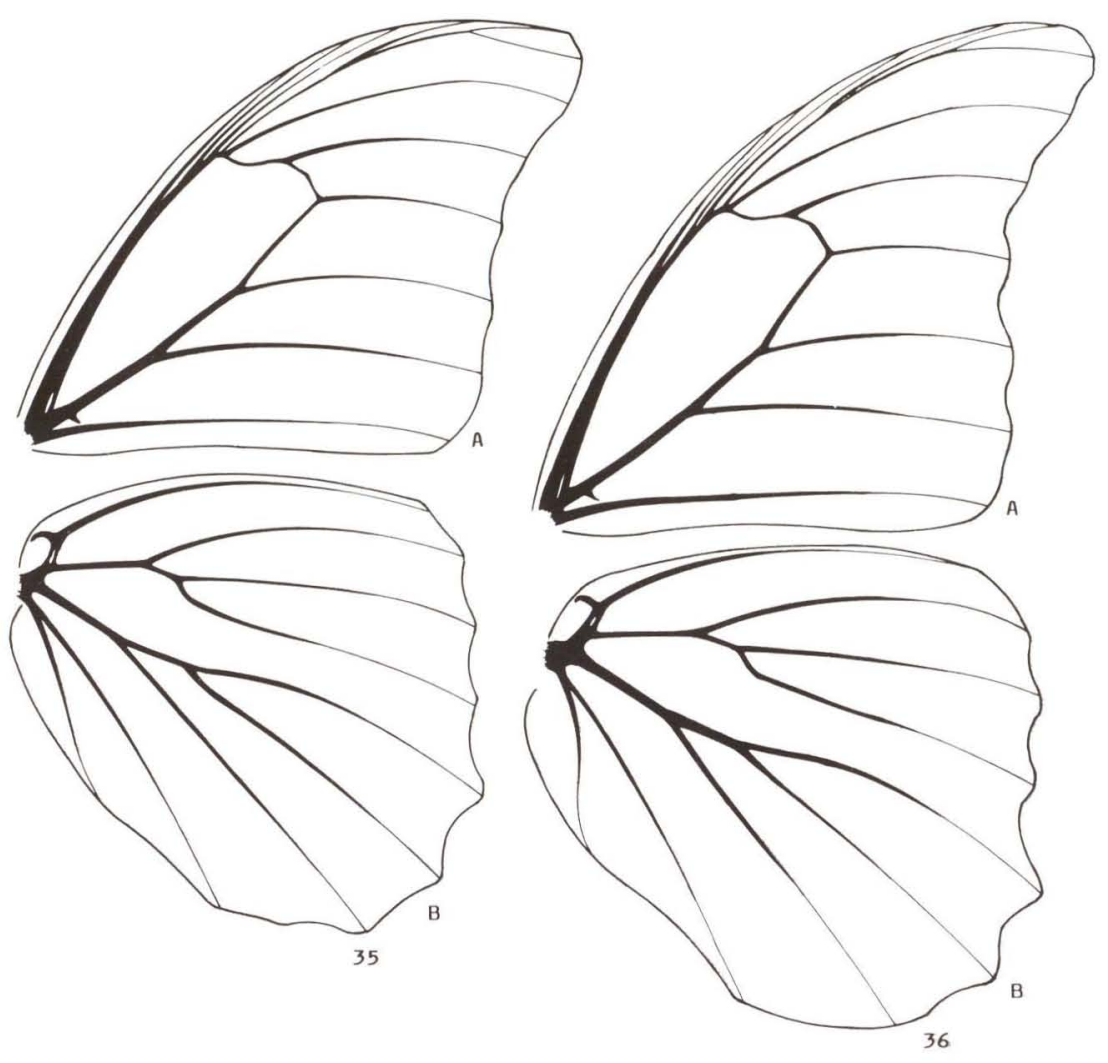

Figs 35-36. Venação, G. menelaus nestira. (35) Macho; (36) fêmea. (A) asa anterior, (B) asa posterior.

paralelas até atingirem a margem externa. Base do ramo cúbito-anterior apresenta uma pequena veia, pós-cúbito. Em M. helenor violaceus (macho), I. hercules, I. anaxibia e $G$. menelaus nestira a distância m-CuA é maior que a distância $\mathrm{CuA}_{1}-\mathrm{CuA}_{2}$ na base (Figs 23, 25 a 28, 35, 36); M. helenor violaceus (fềmea), $C$. portis thamyris, C. aega e P. catenaria têm essa distância menor (Figs 24, 29 a 34). Com relação às distâncias entre o pós-cúbito e $\mathrm{CuA}_{2}$ e ao comprimento de $\mathrm{m}-\mathrm{CuA}$, em $M$. helenor violaceus, I. hercules (fêmea), $C$. portis thanyris, $C$. aega, $P$. catenaria e $G$. menelaus nestira (fềmea), a primeira distância é maior (Figs 23, 24, 26, 29 a 34, 36); em I. hercules (macho), I. anaxibia e G. menelaus nestira (macho) a primeira é menor (Figs 25, 27, 28, 35).

5) Anal (A): parte da base, corre paralela ao CuA e sem ramificação, estendendo-se até o ângulo anal ou torno.

Célula discal, com início na base, limitada pelas veias $\mathrm{R}, \mathrm{CuA}$ e fechada distalmente por quatro veias: discocelular superior (des) entre Rs e $M_{1}$, discocelular mediana (dem) entre $M_{1}$ e $M_{2}$, discocelular inferior (dci) entre $\mathrm{M}_{2}$ e $\mathrm{M}_{3}$ e a médio cubital (m-CuA). M. helenor violaceus, I. hercules (fêmea), $P$. catenaria 

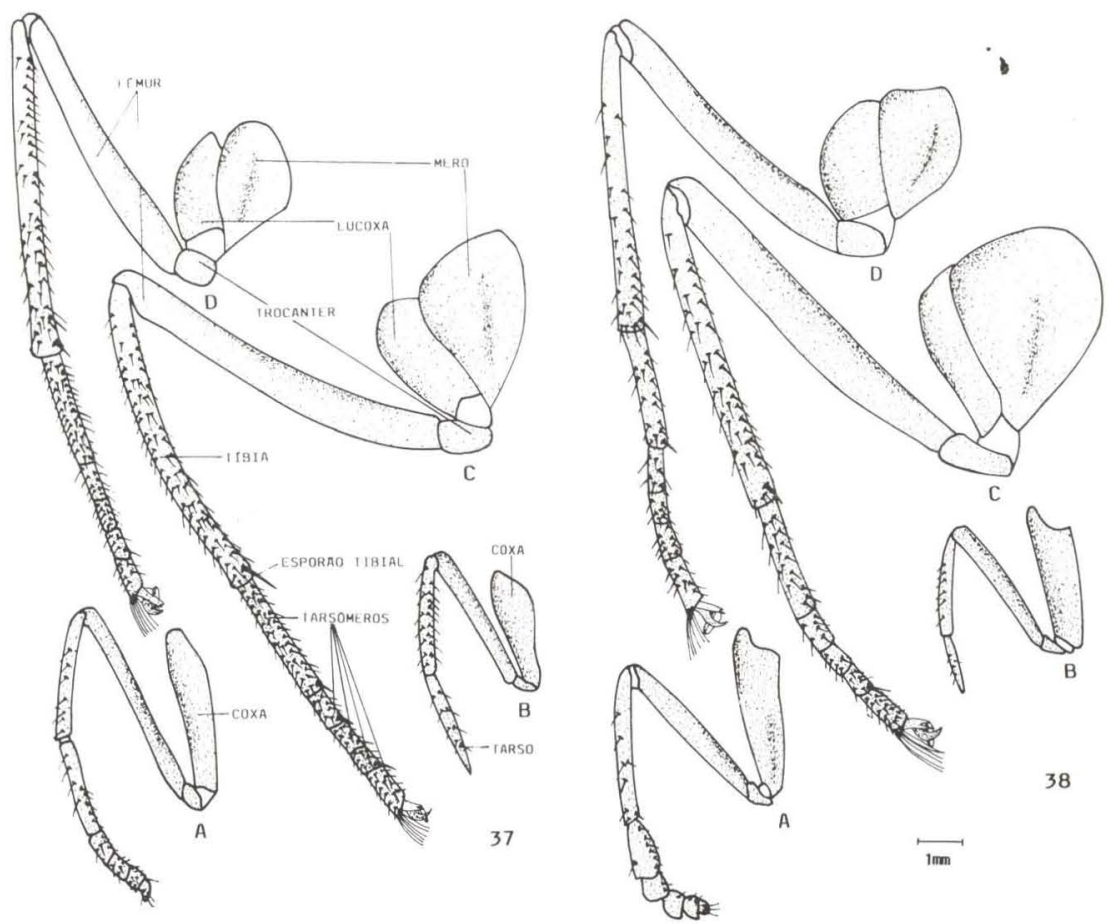

Figs 37-38. Perna. (37) M. helenor violacéus: (38) I. hercules. Fêméa: (A) protorácica: macho: (B) protorácica, (C) mesotorácica, (D) metatorácica.

e G. menelaus nestira (macho), com a dcm maior que a dci (Figs 23, 24, 26, 33 a 35$)$; I. hercules (macho), I. anaxibia, $C$. portis thamyris e $C$. aega (macho), a primeira distância menor (Figs 25, 27 a 31); C. aega (fềmea) e G. menelaus nestira (fềmea) têm o mesmo comprimento entre as duas distâncias (Figs 32, 36).

Asa posterior arredondada e difere da anterior principalmente pela venação. A margem externa ondulada em $M$. helenor violaceus, $I$. hercules, $C$. portis thamyris, $P$. catenaria e $G$. menelaus nestira (Figs 23 a 26, 29, 30, 33 a 36); e não ondulada em $I$. anaxibia e $C$. aega (Figs 27, 28, 31, 32).

$\mathrm{Da}$ base partem unidas $\mathrm{Sc}$ e $\mathrm{R}$ e depois se bifurcam. No início do ramo superior desta bifurcação $\left(\mathrm{Sc}+\mathrm{R}_{1}\right)$ pode estar presente a célula basal. Quando DOUBLEDAY (1846-1852) considerou Morphidae como uma família, generalizou o carácter ausência da célula basal para o gênero Morpho, o qual incluía todas as espécies estudadas no presente trabalho. Depois de estudos detalhados, utilizando a classificação proposta por LE MOULT \& RÉAL (1962-1963) e considerando os subgêneros como gêneros, nota-se que em $M$. helenor violaceus, $I$. anaxibia, $C$. portis thamyris, $C$. aega e $G$. menelaus nestira a célula basal está presente (Figs $23,24,27$ a 32, 35, 36); enquanto que em $I$. hercules e $P$. catenaria ausente (Figs $25,26,33,34)$. Próximo da célula basal parte uma veia transversal pequena, umeral (u), voltada para a base da asa, sem atingir a margem. A Sc $+R_{1}$ continua 

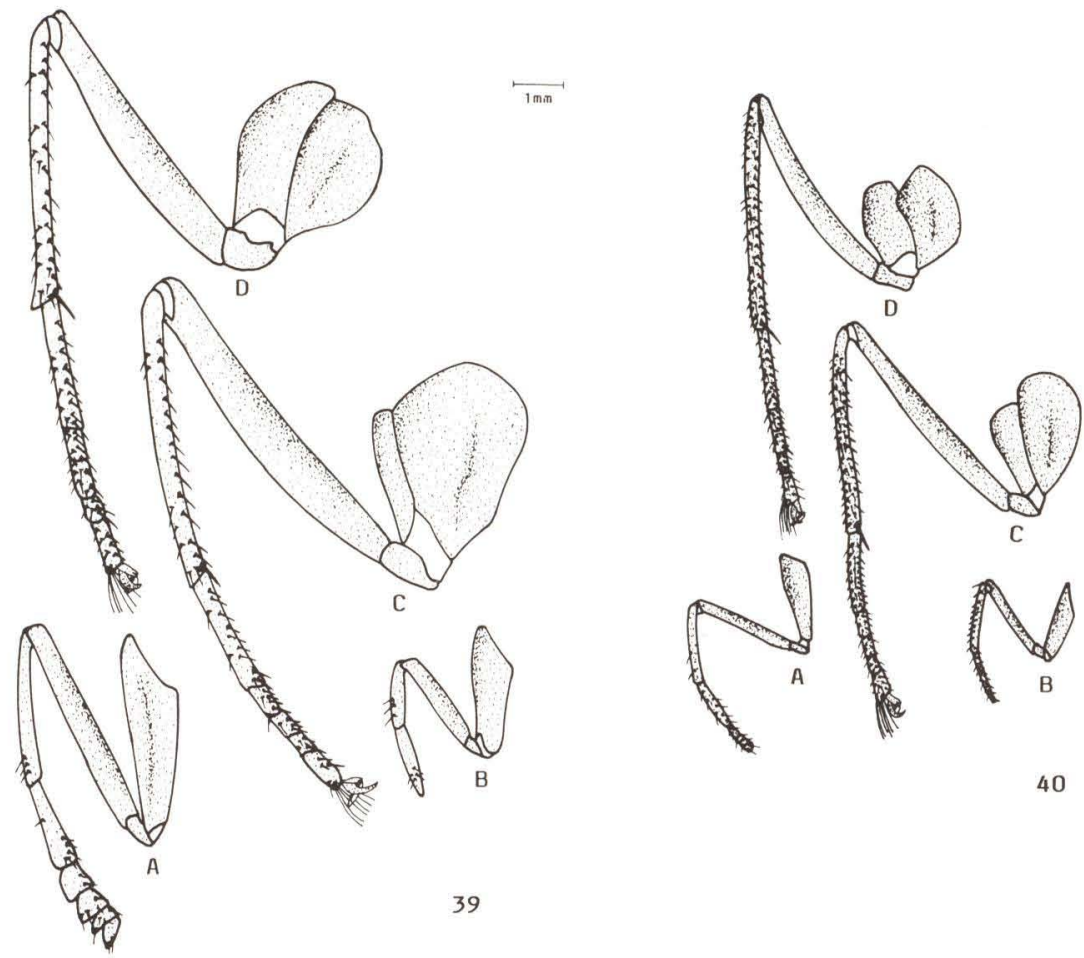

Figs 39-40. Perna. (39) I. anaxibia; (40) C. portis thamyris. Fêmea: (A) protorácica; macho: (B) protorácica, (C) mesotorácica, (D) metatorácica.

após a célula basal e a veia umeral, paralela à margem costal, terminando na margem externa e constituíndo o ápice da asa. O outro ramo da bifurcação, o inferior, setor radial (Rs). A célula discal, com início na base, limitada por Rs, $\mathrm{CuA}$, discocelular superior (des) entre Rs e $\mathrm{M}_{1}$ e discocelular mediana (dcm) entre $\mathrm{M}_{1}$ e $\mathrm{M}_{2}$, sendo a célula aberta pela ausência da discocelular inferior (dci). O cúbito-anterior $(\mathrm{CuA})$ ramifica-se em $\mathrm{CuA}_{1}$ e $\mathrm{CuA}_{2}$. Comparando-se a distância existente entre à base e a bifurcação de $\mathrm{Cu}_{2} \mathrm{em}$ relação à distância entre $\mathrm{CuA}_{1}-\mathrm{CuA}_{2}$, em $M$. helenor violaceus, I. hercules (macho), I. anaxibia (macho), C. portis thamyris, $C$. aega, $P$. catenaria (fềmea) e $G$. menelaus nestira, a primeira distância é maior que a segunda (Figs 23 a 25, 27, 29 a 32, 34 a 36); em I. anaxibia (fềmea) e $P$. catenaria (macho) a distância é a mesma (Figs 28, 33); em I. hercules (fêmea) a primeira distância é menor que a segunda (Fig. 26). Com relação à distância entre a base e a ramificação de Rs em relação à distância entre a base e a ramificação $\mathrm{CuA}_{2}, C$. aega tem a primeira distância menor que a segunda (Figs 31, 32); em G. menelaus nestira com mesmo tamanho entre as distâncias (Figs 35, 36); nas outras espécies, a primeira distância é maior (Figs 23 a 30, 33, 34). Anais $(\mathrm{A})(2 \mathrm{~A}$ e $3 \mathrm{~A})$, partem da base e correm até a margem interna. Os términos da $\mathrm{CuA}_{2}$ e $2 \mathrm{~A}$ limitam o espaço que constitui o ângulo anal (Figs 23 a 36). 


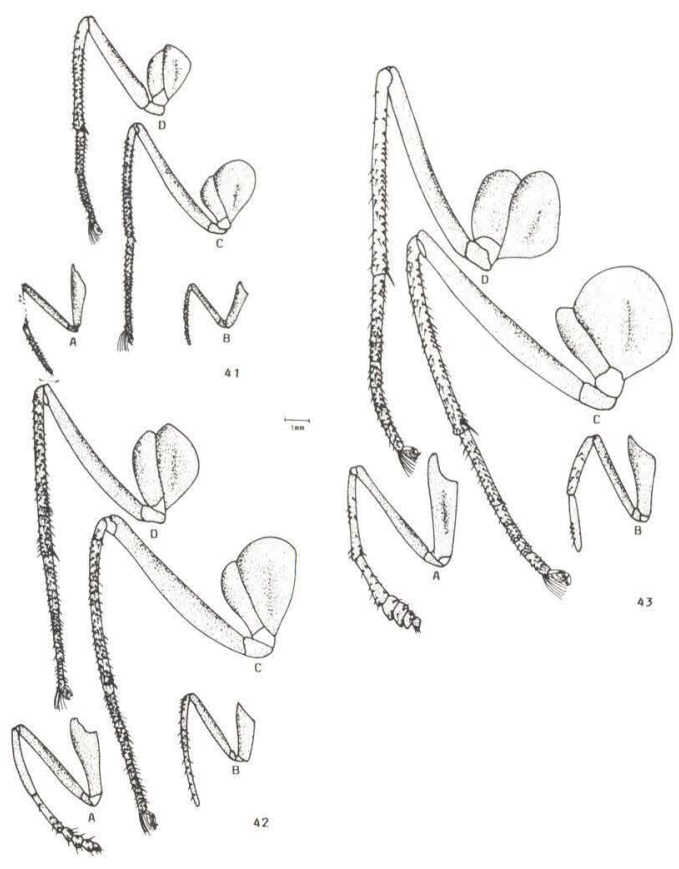

Figs 41-43. Perna. (41) C: aega; (42) P. calenaria; (43) G. menelaus nestira. Fêmea: (A) protorácica; macho: (B) protorácica, (C) mesotorácica, (D) metatorácica.

\section{PERNAS}

Três pares: anterior, mediano e posterior, relacionados com o respectivo segmento do tórax. Cada perna possue: coxa, trocânter, fêmur, tíbia e cinco tarsômeros, exceção da perna anterior do macho com tarso indiviso. Coxa do primeiro par de pernas alongada, mais ou menos cilindrica, mais larga na base. $\mathrm{Na}$ porção basal se articula com a propleura (Figs 37 a 43A-D). As coxas do segundo e terceiro pares de pernas divididas longitudinalmente pela sutura coxal em um esclerito anterior e mais estreito, eucoxa, e em um posterior e mais largo, mero, ambos unidos ao tórax. As coxas se articulam na porção distal com o trocânter, reduzido comparado com o seguinte, o fềmur. Fêmures anterior e médio os maiores artículos, mas na perna posterior menor que a tíbia. Coxa, trocânter e fêmur sem espinhos. Logo após segue-se a tíbia, com um par de esporões tibiais distalmente, este ausente na perna protorácica. Em M. helenor violaceus (macho), I. hercules, C. portis thamyris (macho), C. aega (macho) e G. menelaus nestira (macho), a tíbia protorácica maior que a somatória dos tarsômeros (Figs 37B, 38A, B, 40B, 41B, 43B); em I. anaxibia (macho) e P. catenaria (macho), a tíbia com o mesmo tamanho que a somatória dos tarsômeros (Figs 39B, 42B); em M. helenor violaceus (fềmea), I. anaxibia (fềmea), C. portis thamyris (fềmea), C. aega (fêmea), P. catenaria (fềmea) e G. menelaus nestira (fềmea), a tíbia menor que a somatória dos tarsômeros (Figs 37A, 39 A a 43 A). M. helenor violaceus (fêmea), 


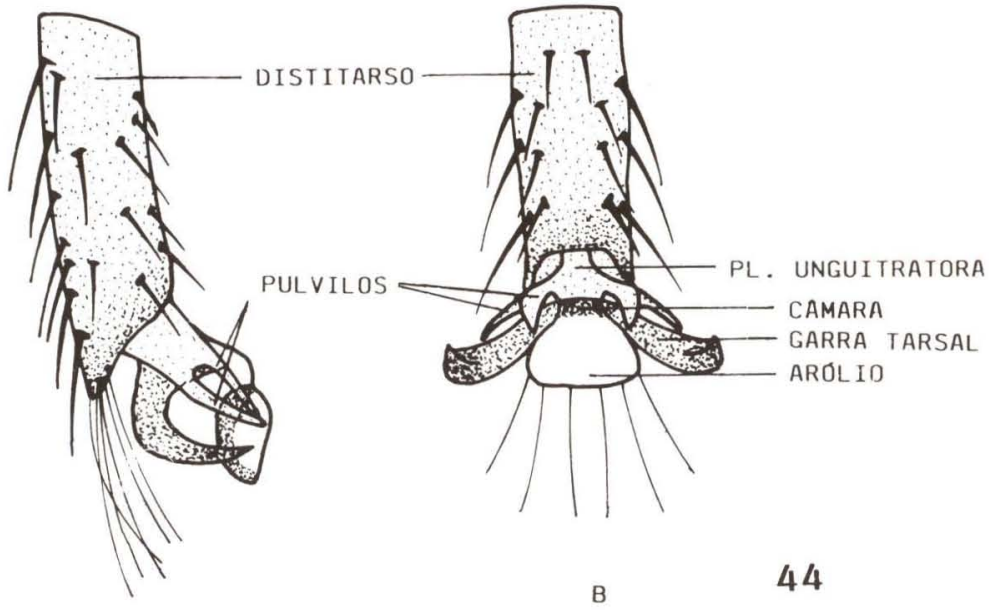

A

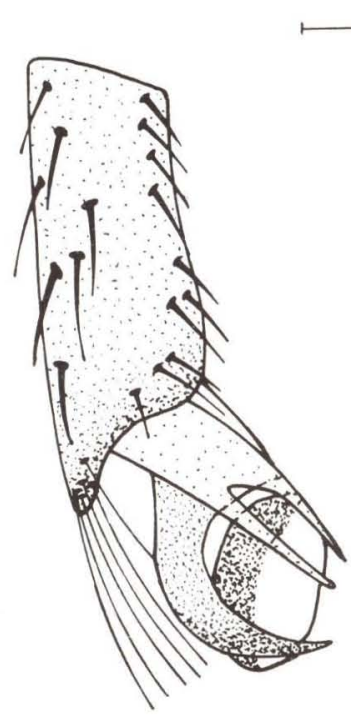

A

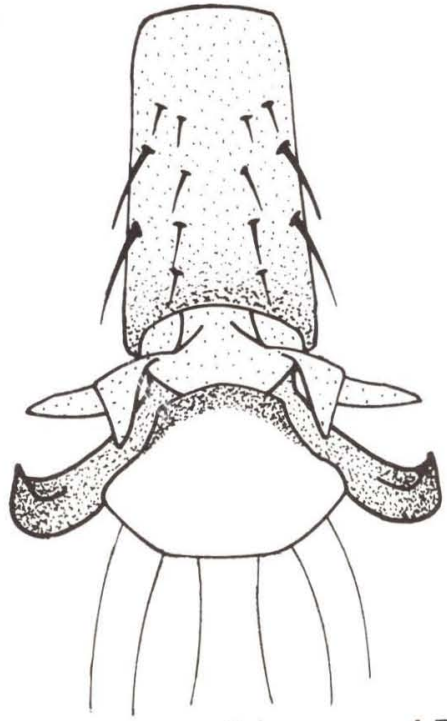

B
45

Figs 44-45. Garra tarsal. (44) M. helenor violaceus; (45) I. hercules. (A) Vista lateral, (B) visa ventral.

I. hercules (macho), I. ancxibia e C. portis thamyris com espinhos na tíbia protorácica somente do lado externo (Figs 37A, 38B, 39A, B, 40A, B); M. helenor violaceus (macho), I. hercules (fêmea), C. aega, $P$. catenaria (macho) e $G$. menelaus nestira com espinhos em todos os lados (Figs 37B, 38A, 41 A, B, 42B, 43A, B); em $P$. catenaria (fêmea) inerme (Fig. 42A). Tíbia metatorácica em $C$. portis thanyris, $C$. aega e $P$. catenaria com espinhos em toda extensão e sem espaços livres (Figs 40D a 42D); em M. helenor violaceus, I. anaxibia, $G$. 

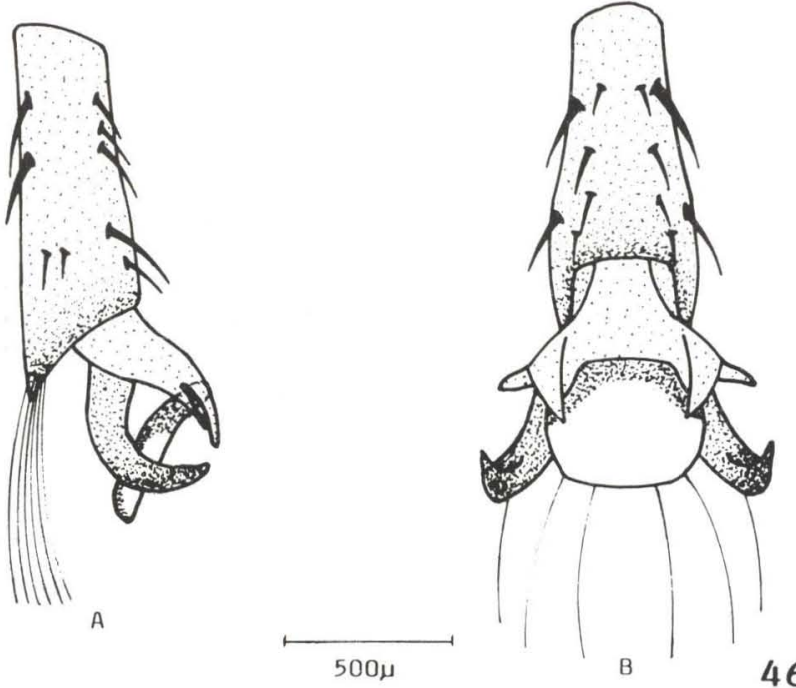

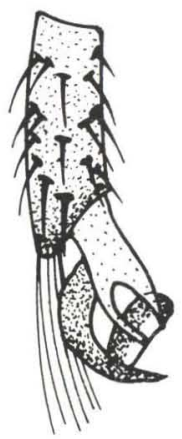

A

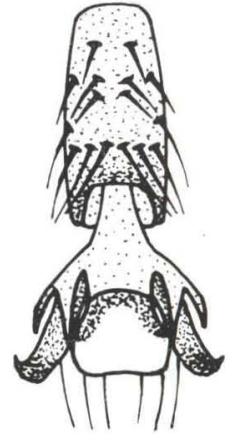

B

47

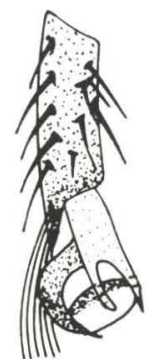

A

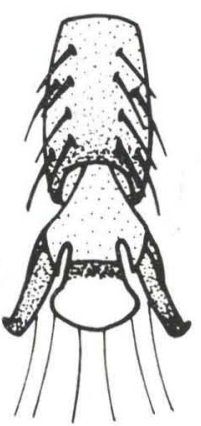

B

48

Figs 40-48. Garra tarsal. (46) I. anaxibia: (47) C. portis thamyris; (48) C. aega. (A) Vista lateral, (B) vista ventral.

menelaus nestira com espinhos em toda extensão, mas com alguns espaços livres (Figs 37D, 39D, 43D); em $I$. hercules, quase todos os espinhos distribuídos na metade distal (Fig. 38D). Articulando-se com a tíbia distalmente está o tarso, subdividido em cinco artículos, tarsômeros, exceto na perna protorácica dos machos, onde o tarso é indiviso. Com exceção de I. hercules (macho), I. anaxibia (macho) e G. menelaus nestira (macho), com espinhos restritos à metade distal do tarso protorácico (Figs 38B, 39B, 43B), o restante das espécies com espinhos em toda extensão (Figs 37B, 40B a 42B). O tarsômero proximal das pernas protorácicas das fêmeas, meso e metatorácicas dos machos sempre maior (Figs 37A, C, D a 43A, C, D). Tarsômero distal, distitarso, com longas cerdas na porção apical (Figs 37C, D a 43C, D; 44A, B a 50A, B). 

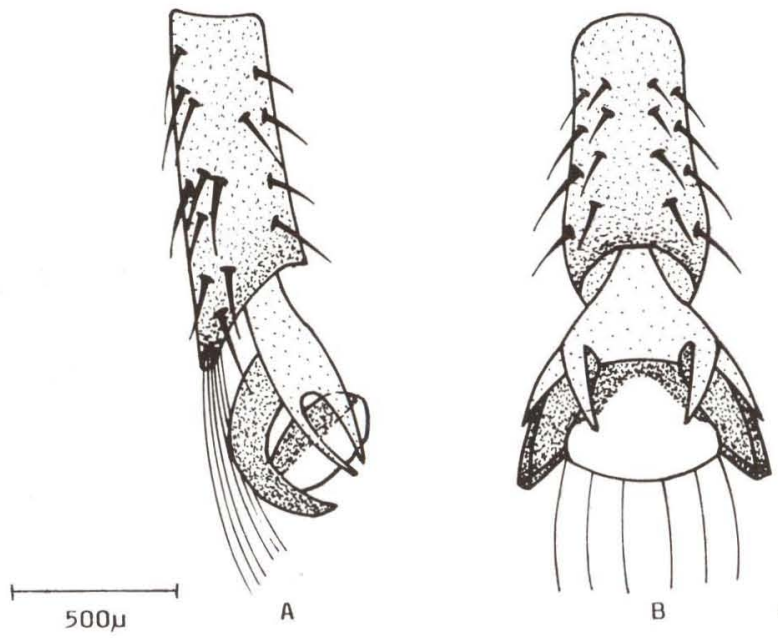

B

49
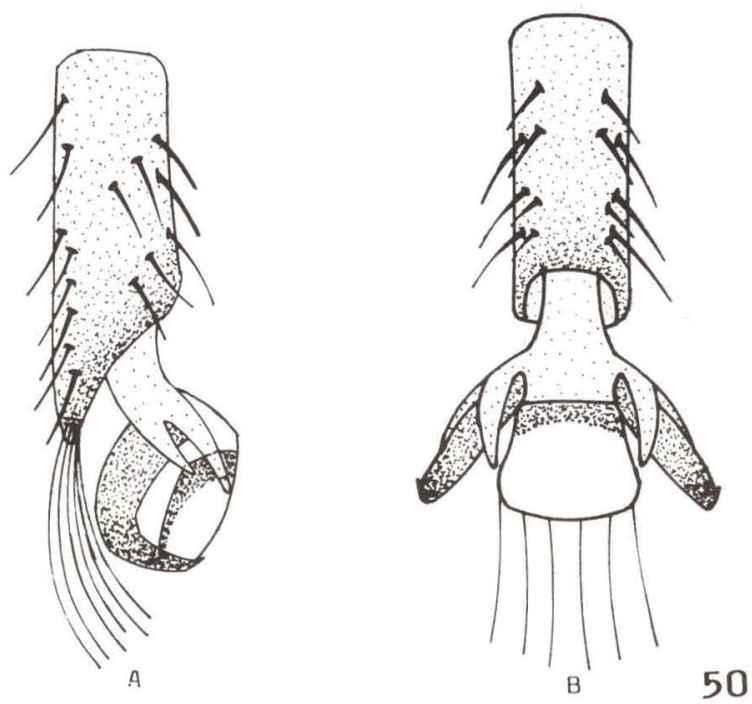

Figs 49-50. Garra tarsal. (49) P. catenaria: (50) G. menelaus nestura. (A) Vista lateral, (B) vista ventral.

Situado na região ventral e partindo do distitarso e fracamente esclerotisada está a placa unguitratora. De cada lado saem dois lobos, pouco esclerotisados e com a porção distal terminando em ponta, pulvilos. Entre os pulvilos e posterior à placa, uma faixa estreita, circular e bem esclerotisada, câmara, que circunda um lobo membranoso, arólio, um par de garras simples, curvas e fortemente esclerotisadas (Figs 44A, B a 50A, B). 
AGRADECIMENTOS. Agradę̧o à Profa. Dra. Mirna Martins Casagrande e ao Prof. Dr. Olaf H.H. Mielke do Departamento de Zoologia da Universidade Federal do Paraná pela orientação e co-orientação.

\section{REFERÊNCIAS BIBLIOGRÁFICAS}

BilotTA, I.G. 1993. Morfologia comparada da cabeça das espécies sulbrasileiras de Morphinae (Lepidoptera, Nymphalidae). Revta bras. Zool. 9 (3/4): 261-271.

Casagrande, M.M. 1979. Sobre Caligo beltrao (Illiger). III: Morfologia externa do adulto-tórax (Lepidoptera, Satyridae, Brassolinae). Rev. Brasil. Biol. 39 (2): 347-355.

COMmON, I.F.B. 1973. Lepidoptera, p.765-866. In: CSIRO (Ed.). The Insects of Australia. Victoria, Melbourne University Press, 1137p.

Costa Lima, A.M. DA. 1950. Insetos do Brasil 6. Lepidópteros. 2a Parte, Morphidae, p. 356-361. Rio de Janeiro, Escola Nacional Agronomia.

CRAmpton, G.C. 1917. The nature of the veracervix or neck region in insects. Ann. Ent. Soc. Amer. 10 (2): 187-197.

D'A Brera, B. 1984. Butterflies of the Neotropical Region. Part II. Danaidae, Ithomiidae, Heliconidae \& Morphidae. Victoria, Hill House, 384p. 1987. Butterflies of the Neotropical Region. Part III. Brassolidae, Acraeidae \& Nymphalidae (Partim). Victoria, Hill House, 525p.

Devries, P.J.; I.J. Kitching \& R.I. VANe-Wright. 1985. The systematic position of Antirrhea and Caerois, with comments on the classification of the Nymphalidae (Lepidoptera). Syst. Ent. 10 (1): 11-32.

Doubleday, E. 1846-1852. The Genera of Diurnal Lepidoptera, comprising their generic characters, a notice of their habits and transformations, and a catalogue of the species of each genus; illustrated with 86 plates by $W$. C. Hewitson. London, 534p.

Eaton, J.L. 1971. Morphology of the Head and Thorax of the Adult Tobacco Horn worm, Manduca sexta (Lepidoptera: Sphingidae). 1. Skeleton and Muscles. Ann. Ent. Soc. Amer. 64 (2): 437-445.

EHRLICH, P.R. 1958a. The Integumental Anatomy of the Monarch Butterfly Danaus plexippus L. (Lepidoptera: Danaiidae). Univ. Kansas Sci. Bull., Lawrence, 38 (18): 1315-i349.

1958b. The Comparative Morphology, Phylogeny and Higher Classification of the Butterflies (Lepidoptera: Papilionoidea). Univ. Kansas Sci. Bull., Lawrence, 39 (8): 305-370.

Fruhstorfer, H. 1912-1913. Morphinate, p. 333-344 (1912), 345-356 (1913), pls. 66-71. In: A. SEITZ (Ed.). Stuttgart, Lehman Gross-Schmett, Erde, 5.

Le Moult, E. \& P. RÉal. 1962-1963. Les Morpho d'Amérique du Sud et Centrale. 1. Historique-Morphologie-Systématique, 296 p. (1962); 2. Planches en couleurs et en noir, 92 pls (1963).

Madden, A.H. 1944. The external morphology of the adult of the Tobacco 
Hornworm (Lepidoptera: Sphingidae). Ann. Ent. Soc. Amer. 37 (2): 145-160.

Matsuda, R. 1970. Morphology and Evolution of the Insect Thorax. Mem. Ent. Soc. Canada 76: 334-355.

Niculescu, E. 1968. L'importance de l'exosquelette pour la Systematique des Lépidoptères. Boll. Ass. Rom. Ent. 23 (2): 33-40. . 1976. La valeur taxonomique des caractères morphologiques chez les Lépidoptères. Bull. Soc. Ent. Mulhouse. p. 1-14.

- 1978. Recherches de morphologie taxonomique dans l'ordre Lepidoptera. Bull. Soc. Ent. Mulhouse. p. 35-40.

Nielsen, E.S. \& F.B. COMMOM. 1991. In: CSIRO (Ed). The Insects of Australia. Carlton, Melbourne University Press, 1137p.

SBORDONI, V.\& S. FORESTIERO. 1985. The world of butterflies, an illustrated encyclopedia. New York, Cies Crescent Books, 312p.

SNODGRass, R.E. 1935. Principles of insect morphology. McGraw-Hill BooK Company. 667p.

STAudinger, O. 1884-1888. In: O. STAudinger \& E. Schatz (Ed.). Exotische Schmetterlinge. I. Theil, Exotische Tagfalter in systematischer Reihenfolge mit Beruecksichtigung neuer Arten. Fuerth, Bayern, p.1-2 (1888); p.3-38, pls 1-30 (1884); p. 39-102, pls 31-60 (1885); p. 103-174, pls 61-80 (1886); p. 175-234, pls 81-95 (1887); p. 235-333, 96-100 (1888). 